\title{
The Influence of a Mathematics Problem-Solving Training System on First-Year Middle School Students
}

\author{
Hsien-Sheng Hsiao ${ }^{1}$, Chien-Yu Lin ${ }^{1}$, Jyun-Chen Chen ${ }^{1 *}$, Yi-Fang Peng ${ }^{1}$ \\ ${ }^{1}$ Department of Technology Application and Human Resource Development, National Taiwan Normal University, TAIWAN
}

Received 6 July 2017 • Revised 14 August 2017 • Accepted 27 September 2017

\begin{abstract}
This study explored problem-solving in middle school, focusing on how students use tools to solve problems when working on mathematical tasks. The Problem-solving Assessment, Diagnosis, and Remedial Instruction (PSADRI) system was designed and developed as an individual teaching tool to support mathematics education, foster students' ability to solve problems. A quasi-experimental design was conducted during five weeks. The 153 students who participated in this experiment were divided into an experimental group (86 students who used the PSADRI system) and a control group (67 students who received traditional instruction). The results revealed that the students who used the PSADRI system achieved greater learning performances in mathematics and improved problem-solving ability compared with the students who received traditional instruction. Using the question-guided training function in the system, the students in the experimental group used the drill-and-practice strategy to solve math problems step by step to achieve mastery in mathematics learning. Moreover, the students' learning performance in the experimental group was enhanced and their problem-solving ability was improved. The major contributions of this study were the improvement in middle school students' academic achievement in mathematics and problem-solving ability and enhanced interest in mathematics learning via the PSADRI system, an individual teaching system.
\end{abstract}

Keywords: problem-solving, mathematics learning, remedial instruction, computerassisted instruction

\section{INTRODUCTION}

In daily and in professional life, people often have to solve personal problems that they encounter (Hsiao, Chang, $\mathrm{Chen}, \mathrm{Wu}, \& \mathrm{Lin}, 2015)$. Problem-solving in mathematics reflects people's problems and phenomena in life, which permeates both the world around them and their mind within (Schoenfeld, 2009). The rhetoric of problem-solving, in which people evoke a mental model or a cognitive representation to solve problems on whatever topic or activity they have in mind, was propagated in mathematics education in the 1980s and 1990s (Lester, 1994; Schoenfeld, 2014).

The cognitive skills of mathematics in elementary and middle school include conceptual understanding, computation skills, and problem-solving (Yung \& Paas, 2015). Undoubtedly, problem-solving is regarded as one of the most important cognitive skills (Hsiao, Chang, Lin, Chang, \& Chen, 2014) and it is considered the most important cognitive activity in processing mathematical problems (Hsiao et al., 2015; Kloosterman \& Stage, 1992; Pape \& Wang, 2003). Developing the ability to solve a wide variety of complex mathematics problems is a primary goal of mathematics teaching and learning (Wilson, Fernandez, \& Hadaway, 1993). Likewise, a large body of literature (e.g., Elia, van den Heuvel-Panhuizen, \& Kolovou, 2009; Ge \& Land, 2003; Kim \& Hannafin, 2011; Lee \& Chen, 2009) has shown that students should be encouraged to engage in non-routine mathematical problem-solving tasks; this allows students to see the meaning and relevance of what they learned, which in turn facilitates the transfer of contextual knowledge to authentic situations. The acquisition of mathematical knowledge through

(C) Authors. Terms and conditions of Creative Commons Attribution 4.0 International (CC BY 4.0) apply. 


\section{Contribution of this paper to the literature}

- A Problem-solving Assessment, Diagnosis, and Remedial Instruction (PSADRI) system was developed to support mathematics education and foster students' problem-solving ability.

- Middle school students' academic achievement in mathematics, problem-solving ability, and interest were improved in learning mathematics via the PSADRI system.

- The question-guided training function and instruction materials provided the students with more effective and convenient tools to practice mathematical word problems in accordance with their errors.

problem-solving has long been considered a crucial instruction strategy to improve the cognitive processing of mathematical word problems and to enhance students' academic achievement (Erbas \& Okur, 2012; Pape \& Wang, 2003).

Unfortunately, many students emphasize the improvement of their arithmetic capability rather than learning how to seek solutions, explore patterns, and formulate conjectures while practicing mathematical exercises (Brown, Fluck, Wilson, \& Fitzallen, 2008; Kloosterman \& Stage, 1992). Boonen, van Wesel, Jolles, and van der Schoot (2014) indicated that conceptual understanding through reading the context of mathematical word problems plays an import role in problem-solving. However, one of the problem-solving skills children have been found to have difficulties with is the ability to comprehend the conception of a mathematical word problem (Schoppek \& Tulis, 2010; Walkington, Clinton, Ritter, \& Nathan, 2015). As there is a strong relationship between reading comprehension and solving mathematical word problems, how to improve these skills while learning mathematical skills has become an important issue in achieving effective, meaningful learning through problem-solving (Lee \& Chen, 2009). For example, first-year middle school students do not understand mathematical word problems involving liner equations, so they cannot generate polynomials and solve the problems.

Problem-solving can be regarded as a helpful learning activity in mathematics education; however, guiding students in their problem-solving process, grading students on their problem-solving ability, and providing individual feedback is very difficult and time-consuming for teachers (Figueira-Sampaio, dos Santos, \& Carrijo, 2009; Martín \& Rubio, 2009). In teaching students how to solve linear equations with two variables in mathematics education in Taiwan, it is difficult for teachers to evaluate and diagnose the conceptual understanding of the addition and subtraction of the same variable that is associated with an error in changing signs when adding and subtracting two polynomials.

Moreover, traditional paper-based remedial instruction cannot provide personalized remedial materials for each student according to individual error types (Hsiao et al., 2016). Given that it is difficult to provide students with personalized lessons and feedback using the face-to-face teaching method, this research will show other significant challenges faced by teachers in Taiwan.

With advances in computing technology, integrating computer-assisted assessment and feedback (CAAF) allows students to individually practice arithmetic problems, find out what their learning faults are, and improve their conceptual understanding (Maier, Wolf, \& Randler, 2016; Schoppek \& Tulis, 2010; van der Kleij, Eggen, Timmers, \& Veldkamp, 2012). CAAF has minimized some difficulties by allowing students to individually access interactive materials and obtain just-in-time assistance in different problem-solving processes (Kim \& Hannafin, 2011). One of the strengths of CAAF is the provision of a problem-solving guide that provides students with correct knowledge and elaborated explanations of their misconceptions and confusion when they generate errors in different steps of problem-solving (Maier et al., 2016; Sung, Liao, Chang, Chen, \& Chang, 2016; van der Kleij et al., 2012).

Many researchers have indicated that employing CAAF to provide personalized teaching and remedial materials is essential to improving students' learning behaviors (de-Marcos, Garcia-Lopez, \& Garcia-Cabot, 2016; Hsiao et al., 2014) and academic achievement in different disciplines (Hsiao et al., 2015; Hsiao, Chang, Lin, \& Wang, 2016; Walkington et al., 2015; Yung \& Paas, 2015). From a practical point of view, the mathematical ability of each student may contribute to the interpretation of individual differences in problem-solving. CAAF can provide suggestions on how to support student development in solving problems according to the results of students' conceptual understanding as evaluated and diagnosed by well-structured declarative knowledge (Sim, Holifield, \& Brown, 2004). Moreover, CAAF has the advantage of flexibility, which means that each student takes the test when he/she is ready and confident in doing so (Croft, Danson, Dawson, \& Ward, 2001)

In light of the above, this study focused on the problems and issues inherent in students' problem-solving processes through technology use in the classroom. First, the importance of the problem-solving process during the solution of a problem, namely the four steps of problem translation, problem integration, solution planning and monitoring, and solution execution, was considered, and then a mathematical training system that included a problem-solving guide, mathematical ability diagnosis, and just-in-time feedback for students as they solved problems was developed for use in a technology-rich classroom. Next, the research and practices related to 
academic achievement, ability to solve problems, and problem-solving habits were analyzed and, finally, the implications of the research were examined.

\section{THEORY AND FRAMEWORK}

Students need to be guided step by step during the problem-solving process. Because problem-solving is regarded as a particular learning outcome for life, it does not mean that an individual carries out only simple tasks in his/her daily life (Baltac1, Yıldız, \& Güven, 2014; Hsiao et al., 2015; Lester, 1994). As the difficulty of reasoning and calculating required for solving problems increases, the ability to solve problems requires both short- and longterm memory, organization, and mental flexibility for task completion (Schoenfeld, 2009; Whitby, 2013). Moreover, Mayer (1992) described the four stages in solving a problem: problem translation, problem integration, solution planning and monitoring, and solution execution.

This study combined Mayer's (1992) stages in solving a problem and developed a mathematical training system with the functions of assessment, diagnosis, and feedback during different steps. Using the training system designed and developed for this study, students should learn how to solve a problem more efficiently and in less time compared with traditional teaching methods, since traditional paper-based remedial instruction methods cannot provide personalized remedial instruction for each learner according to individual error types. Thus, this study hypothesized that the training system would make a positive impact on students' academic achievement in mathematics.

Hypothesis 1: The students who used the training system will score significantly higher in academic achievement compared with the students who received traditional instruction.

Hypothesis 2a: The students who used the training system will score significantly higher in problem translation compared with the students who received traditional instruction.

Hypothesis 2b: The students who used the training system will score significantly higher in problem integration compared with the students who received traditional instruction.

Hypothesis 2c: The students who used the training system will score significantly higher in solution planning and monitoring compared with the students who received traditional instruction.

Hypothesis 2d: The students who used the training system will score significantly higher in solution execution compared with the students who received traditional instruction.

Hypothesis 3: The students who used the training system to learn how to solve problems will score significantly higher in "perceptions toward mathematics learning" compared with the students who received traditional instruction.

Hypothesis 4a: Initial academic achievement will be positively associated with students' academic achievement in the experimental group.

Hypothesis 4b: Initial academic achievement will be positively associated with students' academic achievement in the control group.

Hypothesis 5a: The ability to solve problems will be positively associated with students' academic achievement in the experimental group.

Hypothesis 5b: The ability to solve problems will be positively associated with students' academic achievement in the control group.

In this study, perceptions toward mathematics learning, meaning that the problem-solving behavior of students was changed by either the teacher or the training system in the process of solving problems, include three aspects attitude and interest, mathematical value, and motivation. "Attitude" is a person's response to a particular thing, while "interest" is the attitude of a person who is willing to be actively engaged in a task, learning content, or learning class. "Mathematical value" refers to the degree of attention to mathematics (Lin, 2007). Students who have a higher mathematics value will have more positive achievement motivation (Chen \& Yu, 2013). "Motivation" is a driving force of behavior and plays an important role in the learning process. Much research has shown that learning motivation positively influences learning performance (Burguillo, 2010; Pintrich \& De Groot, 1990; Rau, Gao, \& Wu, 2008).

The process of solving mathematical word problems is far more than just calculation, deduction, multiplication, and division; it involves the comprehension of textual meaning, decomposing the problem, testing conjectures, and evaluating and verifying the results (Mayer, 1992; Schoenfeld, 2009; Verschaffel et al., 1999). Bjork and BowyerCrane (2013) indicated that during the problem-solving process, students often encounter incomprehension of textual meaning, less familiar syntax and diction, and an inconsistent order of the problem steps, leading to less accuracy in problem-solving. Moreover, students should be provided with enough resources to improve their process of solving problems (van der Kleij et al., 2012). Therefore, the training system should provide more 
opportunities for assessment, diagnosis, and problem-solving via a guide rather than text only; for example, support feedback could be delivered via images, video, or audio. Hence, this study explored whether the mathematical academic achievement of students was enhanced when their ability to solve problems improved.

\section{METHODS}

This study aimed to foster middle school students' ability to solve mathematical problems and improve their reading comprehension and the process of solving mathematical word problems through a mathematical training system. A quasi-experimental approach was used to look for differences in learning performance and behavior patterns between the students who used the training system and those who received traditional instruction to improve their problem-solving ability. The course adopted in this study was the unit on linear equations with two variables for first-year middle school students. This study designed the contents of the training system in accordance with the competency indicators of mathematics for the seventh grade.

\section{SUBJECTS}

The 153 students who participated in this study were seventh graders from a middle school in Taipei. The students came from seven classes and their ages ranged from 13 to 14 . Four classes were assigned to the experimental group and the other three classes comprised the control group. The students in the experimental group and the control group learned the same teaching content and carried out the same activity procedures with different teachers. The training system was used for assessment, diagnosis, and teaching guided mathematical problem-solving in the experimental group, whereas the control group participated in traditional instruction as shown in Figure 1 below:
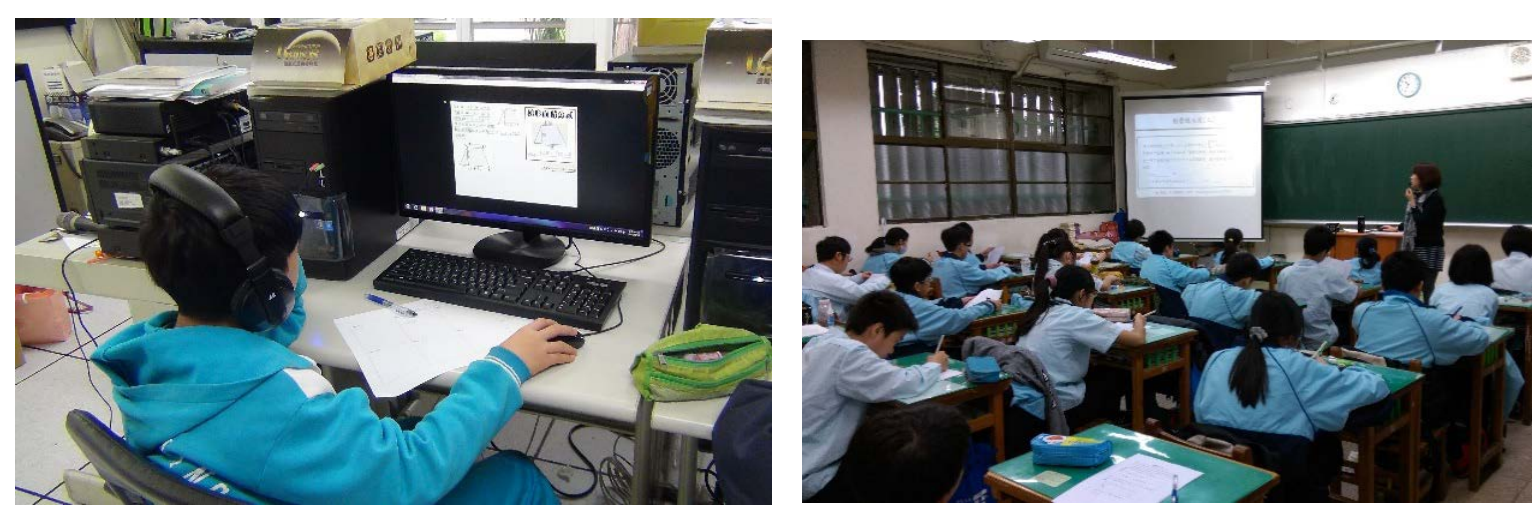

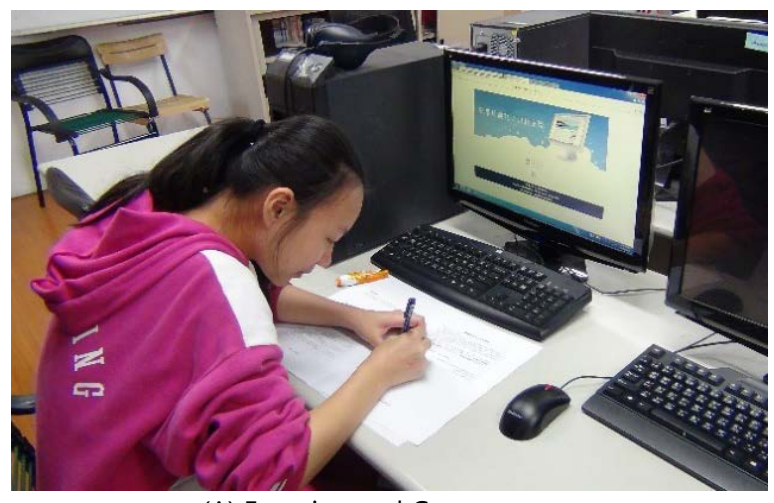

(A) Experimental Group

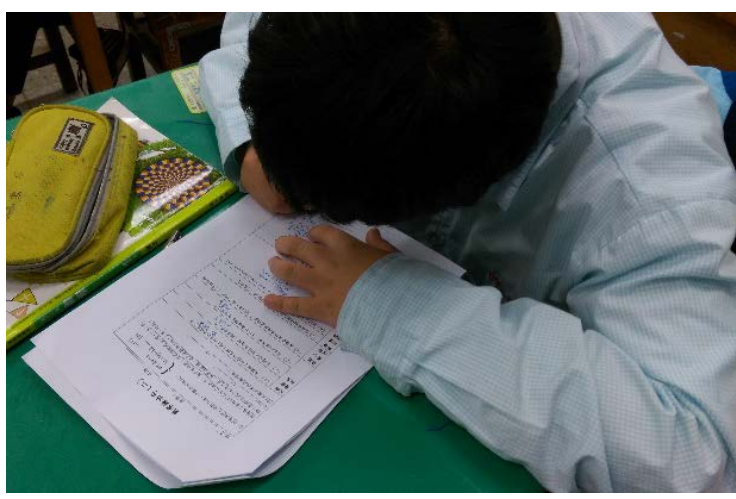

(B) Control Group

Figure 1. The learning process

\section{PROCEDURE}

The approach of this study adopted the experimental design of a non-equivalent pre-test/post-test control group. The period of the experiment was five weeks. The procedure of the experiment is shown in Figure 2 . The students in this experiment were separated into two groups (the experimental group had 86 students and the 


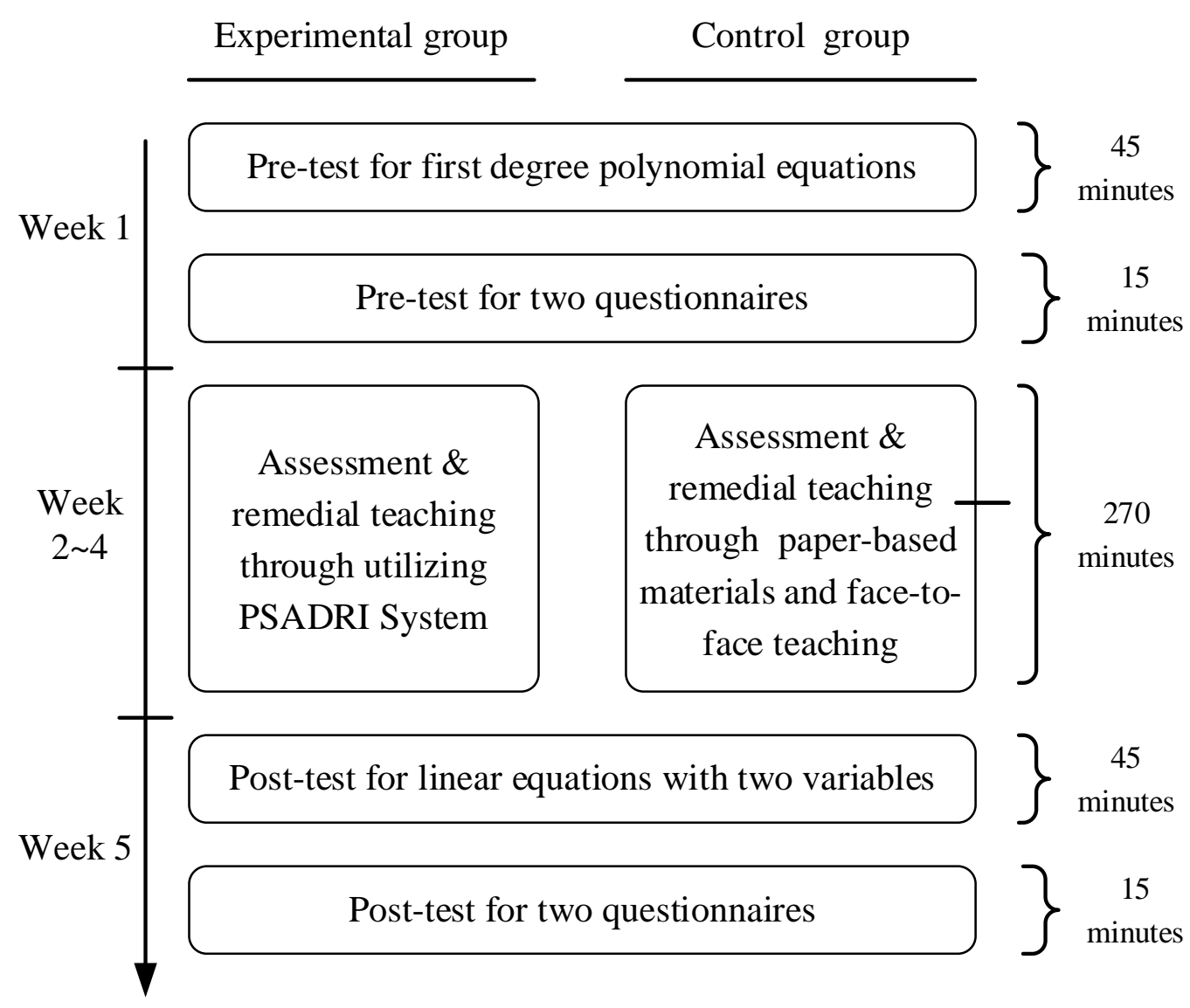

Figure 2. Experimental procedure

control group had 67 students). All of the students took pre-tests at the beginning of the course. The pre-tests included one test of mathematical academic achievement and a questionnaire on students' perceptions toward mathematics learning. The two groups, having already completed the pre-test, commenced with the course. The experiment continued for three weeks, and each week featured one experimental activity lasting 90 minutes. All of the students took post-tests to measure their learning performance after carrying out the learning activity and to quantify the range of their sense and perceptions toward mathematics.

The experiment activity focused on the problem-solving steps designed by Mayer (1992). In particular, the activity theory shed light on how students utilized the problem-solving steps to acquire the solutions to the math problems. Additionally, during the problem-solving process, the students needed to follow Mayer's four problemsolving steps: problem translation, problem integration, solution planning and monitoring, and solution execution. Problem translation: students extract geometric concepts from the textual description of the problem using linguistic and semantic knowledge. Problem integration: students need to integrate the problem's concept with an illustration from the information provided by the problem. Solution planning and monitoring: students develop a plan to solve the problem and monitor the solution according to their understanding of the problem. Solution execution: Students finally execute the solution to get the answer.

\section{PROBLEM-SOLVING ASSESSMENT, DIAGNOSIS, AND REMEDIAL INSTRUCTION SYSTEM}

The study employed PHP 6, HTML, and CSS to design and develop the Problem-solving Assessment, Diagnosis, and Remedial Instruction (PSADRI) system (see Figure 3). The system was comprised of a three-tier structure. The end-user system was installed on a Windows 7 OS. The server side was built on Windows 2008 and used Internet Information Services (IIS) as the Web server platform. The My-SQL database was used as the management system. 


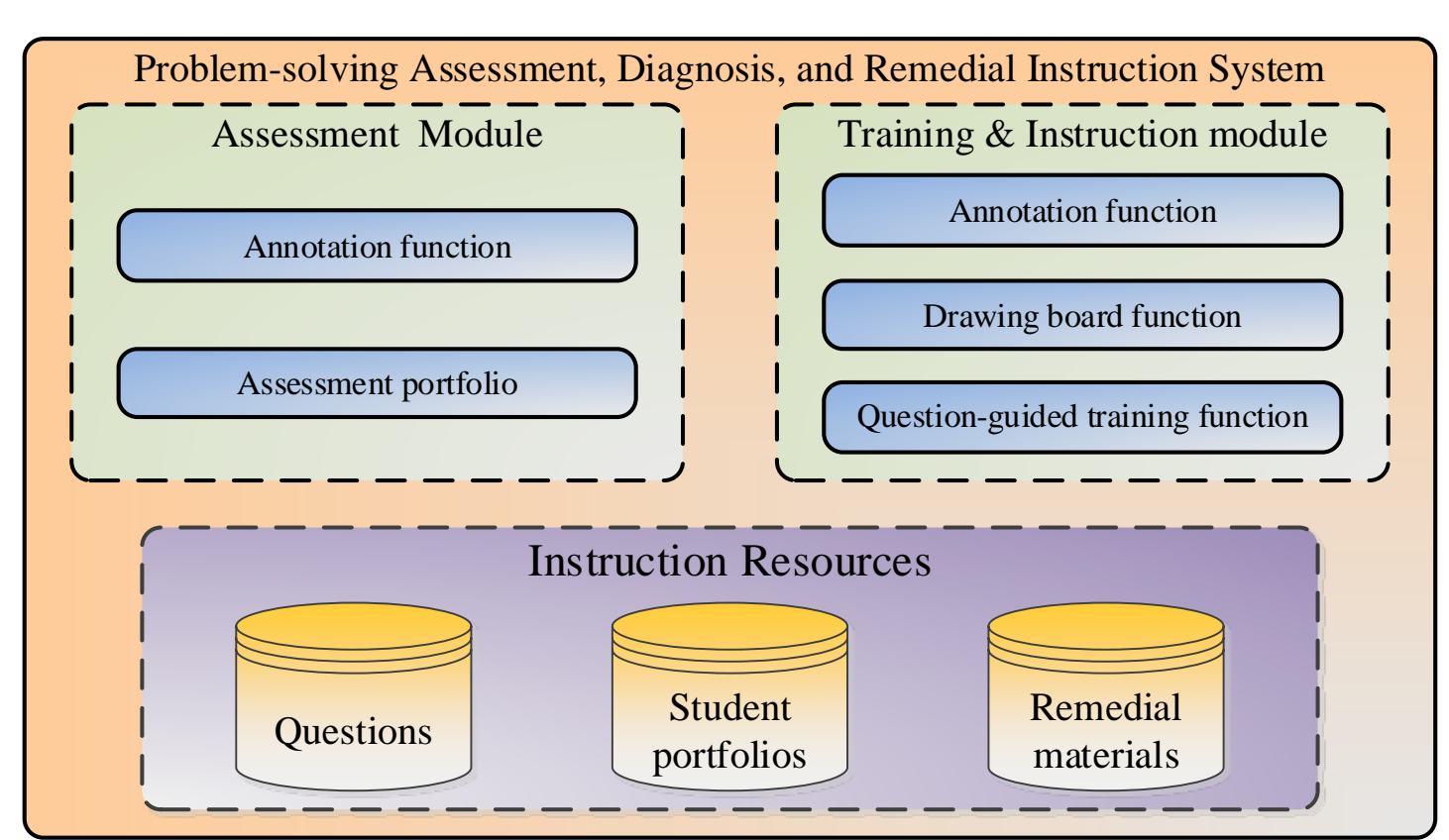

Figure 3. System architecture

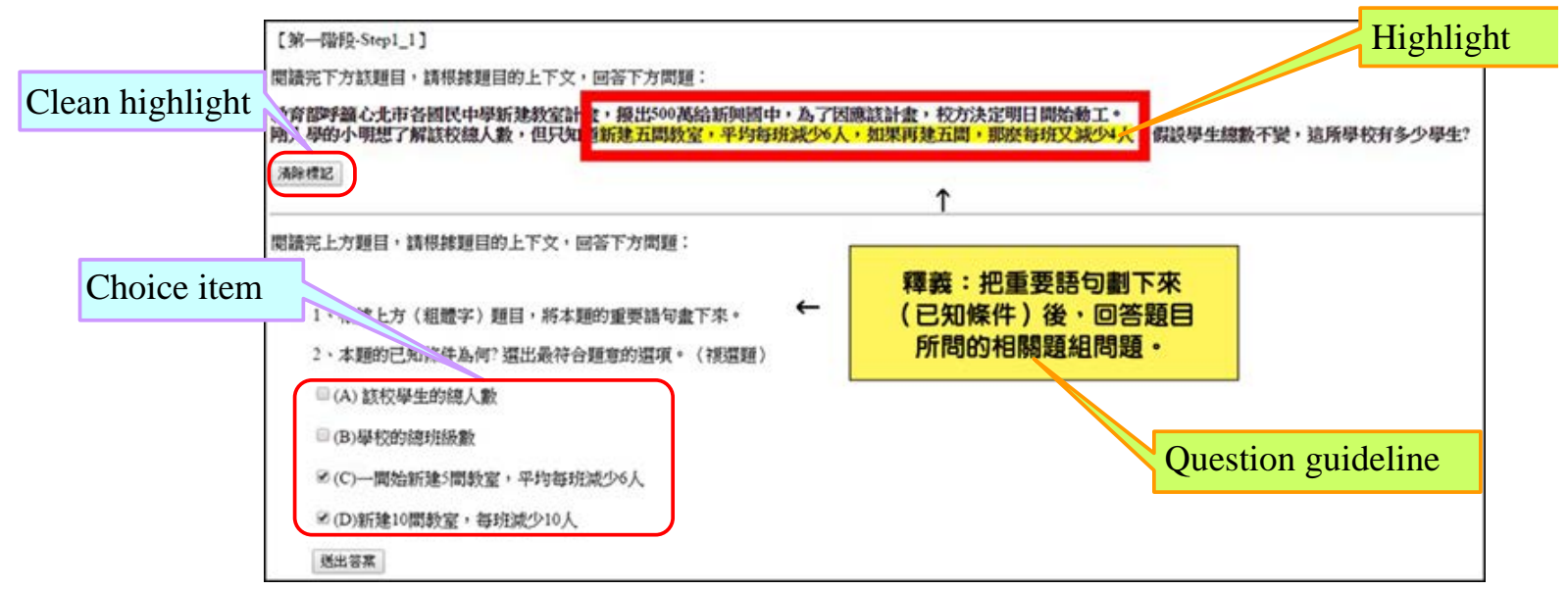

Figure 4. Annotation function

The unit on linear equations with two variables in the first-year middle school course was installed in the mathematical training system to assess, diagnose, and teach the children mathematical problem-solving. The database for the PSADRI system included a question bank, student portfolios, and remedial materials. The question bank contained the questions and the answers for assessment. The student portfolios were used to record their scores so they could see their errors. The remedial instruction materials provided the students with a personalized teaching guide.

The PSADRI system was based on the problem-solving steps designed and developed by Mayer (1992). The PSADRI system included two main modules: the assessment module and the training and instruction module. The assessment module had three functions, namely, annotation function, and assessment portfolio. The annotation function was used to highlight the point of the question, which assisted students in extracting geometric concepts and choosing the correct item by reading the textual description of the problem (see Figure 4). Moreover, the assessment portfolios were used to record the learners' scores, errors, and the analysis of error types when they took the tests so they could see their errors after the tests.

The training and instruction module provided personalized training and instruction for students based on their errors, which were provided by their assessment portfolio. The module included two new functions: a questionguided training function and a drawing board function. The question-guided training function not only emphasized the advantage of multimedia technology but also provided each student with suitable teaching materials to foster reading comprehension of mathematical word problems (see Figure 5). 


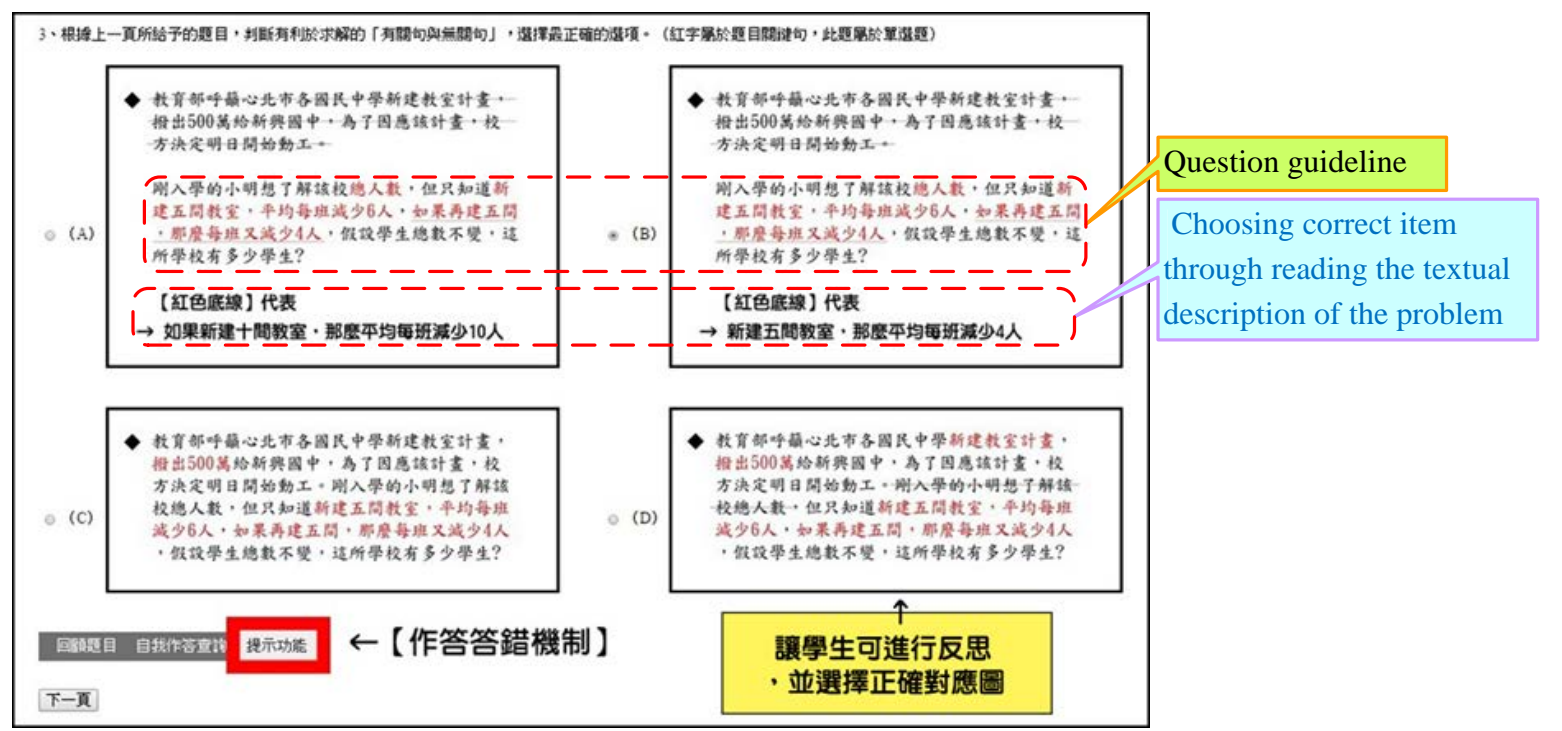

Figure 5. Question-guided training function—extracting geometric concepts

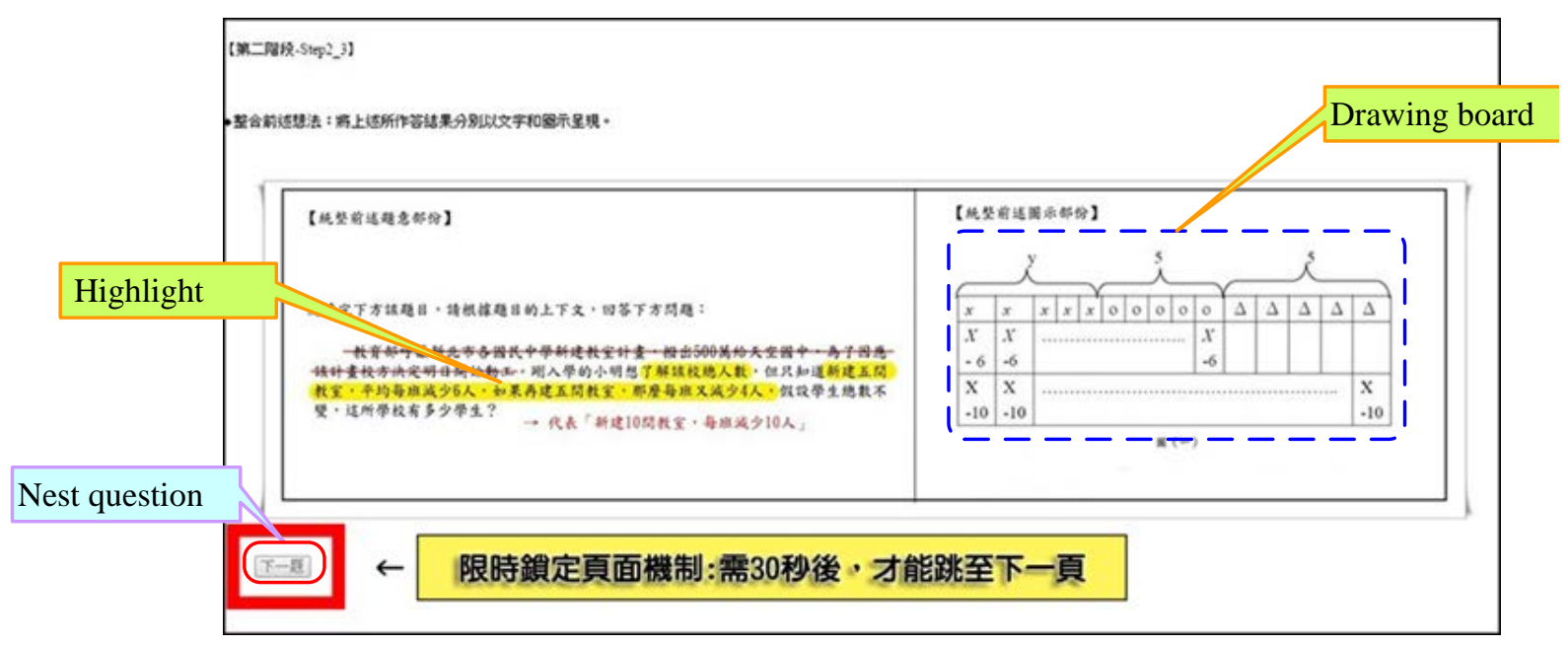

Figure 6. Drawing board function-integrates the problem's concept with an illustration

A common mistake in problem-solving is that alternatives are evaluated as they are proposed, so the first acceptable solution is chosen, even if it is not the best fit. Students could integrate the problem's concept with an illustration from the highlighted information using the drawing board function (see Figure 6). Moreover, students could use a series of considerations when selecting the best alternative according to their concept of understanding the problem (see Figure 7).

\section{MEASUREMENTS}

Two tests, one questionnaire, and one scoring criterion were designed and used to collect data. The tests, including a pre-test and a post-test, were used to evaluate the student's mathematical academic achievement. The questions on the pre-test and post-test, composed from the unit on linear equations with two variables, were used to evaluate the student's learning performance in different learning activities. Following the design of the test, drafts of the two tests were reviewed and edited by three professors with mathematics backgrounds to verify and modify the appropriate statement of items, as well as construct expert validity. The two tests contained 10 mathematical word problems. As for calculating the score for each question, students earned 10 points if they answered the question completely; the maximum score for each test was 100 points. As for reliability, the researcher adopted the internal consistency coefficient, obtaining a Cronbach's alpha of .703.

The questionnaire on the students' perceptions toward mathematics learning was designed and developed based on Snow, Corno, and Jackson's (1996) study. It adopted a 5-point Likert scale (from "1" being "strongly 


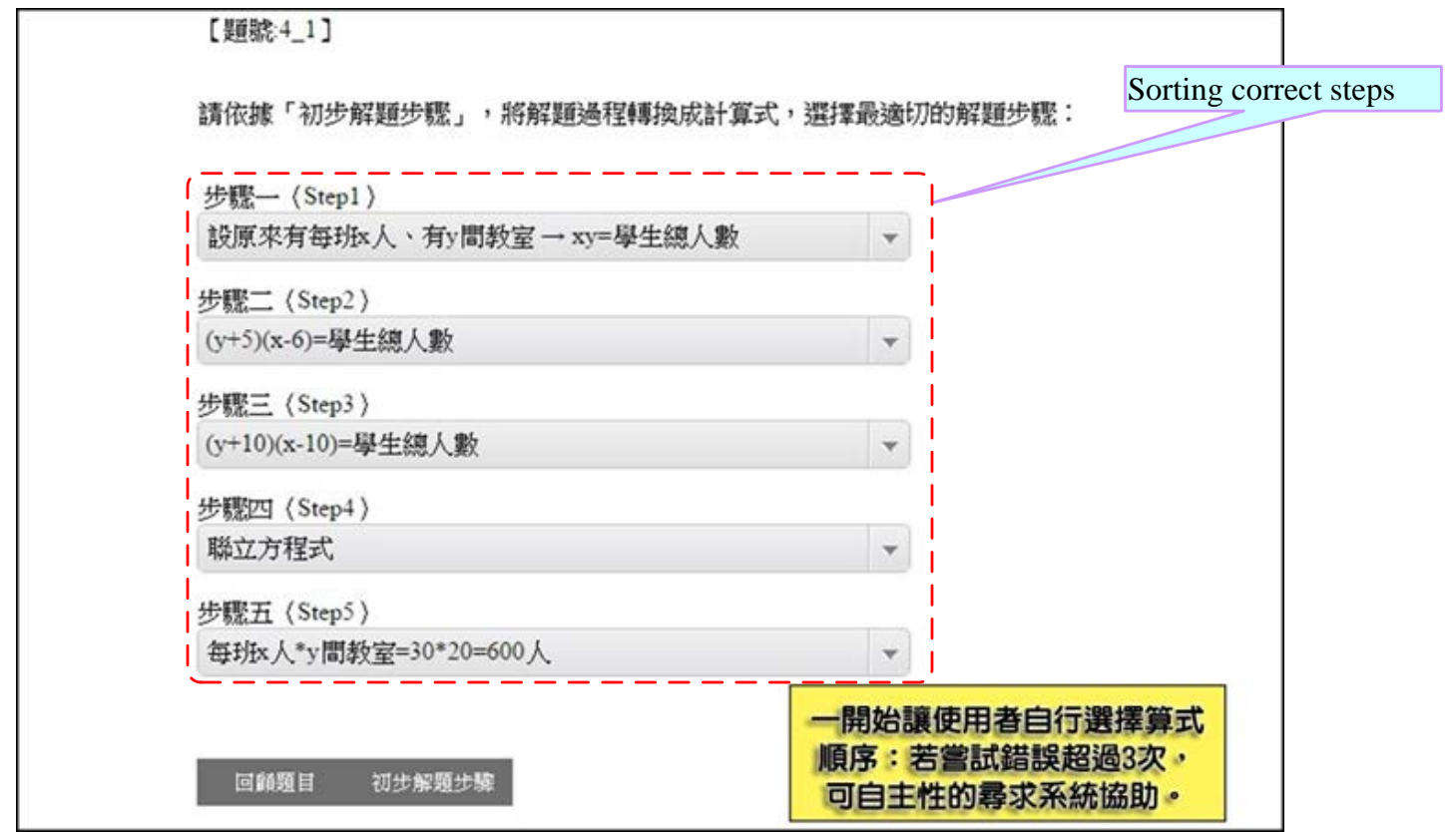

Figure 7. Question-guided training function—solution planning and monitoring

disagree" to " 5 " being "strongly agree"). The questionnaire had 31 items and three factors, namely, attitude and interest, mathematical value, and motivation. The cumulative percentage of variance was $69.81 \%$, and the factor loading for every factor loading was 0.05 . The three factors (i.e., attitude and interest, mathematical value, and motivation) were separately measured 10,10, and 11 items, respectively. The Cronbach's alpha coefficient for the three factors was $.894, .859$, and .756 , respectively. The results showed that the questionnaire was considered a valid instrument.

In addition, the scoring criterion of problem-solving ability was used to evaluate students' ability to solve problem by measuring each question of the pre- and post-test. The total score for each student was assessed by two math teachers and converted into a percentile. The scoring criterion of problem-solving ability was designed by Szetela and Nicol (1992) and was modified into the Chinese version by Chin, Lin, Lin, and Tuan (2009). The Cronbach's alpha coefficients for the four items scored were between .703 and .981 and the reliability was .812. Each of the four items had different choices. The scoring criterion is shown in Table 1 below:

Table 1. The scoring criterion for problem-solving ability

\begin{tabular}{|c|c|}
\hline Item & Scoring Criterion \\
\hline \multirow{5}{*}{ Problem translation } & 0 - Did not try to understand. \\
\hline & 1 - Almost misinterpreted the problem. \\
\hline & 2 - Misinterpreted the main part of the problem. \\
\hline & 3 - Misinterpreted the minor part of the problem. \\
\hline & 4 - Understood the problem. \\
\hline \multirow{4}{*}{ Problem integration } & 0 - Did not try to integrate. \\
\hline & 1 - Incorrect integration of the problem and incorrect illustration. \\
\hline & 2 - Incorrect integration of the problem but correct illustration. \\
\hline & 3 - Correct integration of the problem and correct illustration. \\
\hline \multirow{5}{*}{$\begin{array}{l}\text { Solution planning and } \\
\text { monitoring }\end{array}$} & 0 - Did not propose a solution. \\
\hline & 1 - Completely incorrect solution. \\
\hline & 2 - Incorrect solution in the main part of the problem. \\
\hline & 3 - Incorrect solution in the minor part of the problem. \\
\hline & 4 - Correct solution. \\
\hline \multirow{3}{*}{ Solution execution } & 0 - Did not propose solution, leading to incorrect answer. \\
\hline & 1 - Copying errors, calculation errors, missing information, leading to incorrect answer. \\
\hline & 2 - Completely correct answer. \\
\hline
\end{tabular}




\section{RESULTS}

This section will describe the research results, which investigated and verified the five research hypotheses. SPSS 19.0 was used as a statistical analysis tool to show the impact of the PSADRI system on the middle school students. First, a t-test was used to analyze the differences between the pre-tests and post-tests for the experimental group and the control group. Second, one-way Analysis of Covariance (ANCOVA) was used to analyze the differences in learning performance and ability to solve problems between the two pedagogical strategies. Third, linear hierarchical regressions were performed on the data to measure the extent to which achievement in the pretest and initial ability to solve problems positively predicted achievement in the post-test for both the PSADRI system and traditional teaching approaches.

\section{The Effects of Pedagogical Strategies on the Students' Academic Achievement}

The mean $(M)$ and standard deviation (SD) for the experimental group $(M=64.63, S D=21.15)$ and the control group $(\mathrm{M}=52.88, \mathrm{SD}=25.96)$ indicated that there were significant differences in the pre-test $(\mathrm{t}$-value $=3.084, p=$ .002 , Cohen's $d=.496)$. The results showed that the experimental group $(\mathrm{M}=74.48, \mathrm{SD}=19.38)$ and the control group $(\mathrm{M}=58.08, \mathrm{SD}=27.59)$ had significant differences ( $\mathrm{t}$-value $=4.315, p<.001$, Cohen's $\mathrm{d}=.688)$ in the posttest. Moreover, the paired-samples t-test was adopted to compare the differences between the scores of the pretests and the post-tests taken by the two groups. The results showed that there was a significant difference in the unit on linear equations with two variables between the pre-tests and the post-tests of the experimental group, which indicated significant progress ( $\mathrm{t}$-value $=6.196, p<.001$ ). Likewise, the control group had a similar outcome $(\mathrm{t}$-value $=2.644, p=.010)$.

Furthermore, ANCOVA was adopted to measure the post-test, in which the pedagogical strategies (i.e., the PSADRI system and traditional instruction) were the between-groups factor and the pre-tests were treated as a covariate to exclude the difference in mathematical ability between the experimental group and the control group. There was an interaction of minor degree between the pre-test scores and the learning tools $\left(\mathrm{F}_{1,149}=3.791, p=.053\right)$, which showed that the regression slopes of the two learning groups were homogeneous. The results showed that the pre-test scores were the covariate $\left(\mathrm{F}_{1,150}=239.603, p<.001\right)$; the main effect of the pedagogical strategies was significantly different $\left(\mathrm{F}_{1,150}=8.729, p=.004, \mathrm{\eta}^{2}=.055\right)$ in the post-test scores between the experimental group and the control group, and the Adj- $R^{2}$ was .653 . The results revealed that the adjusted-means (adj-M) in learning performance was higher in the experimental group (adj-M $=70.45$, adj-SD $=1.59$ ) than in the control group (adj-M $=63.24$, adj-SD =1.81), after removing the influence of the pre-test. This statistical result supports Hypothesis 1 .

\section{The Effects of Pedagogical Strategies on the Students' Problem-solving Ability}

This study utilized Mayer's (1992) four-step stages of problem-solving to measure the students' ability to solve problems. The independent-sample t-test was employed to compare the discrepancy of the initial ability to solve problems for the students in both groups. The scores of the pre-test were regarded as the students' initial ability to solve problems. Table 2 reveals that the experimental group had a higher initial ability in problem translation ( $\mathrm{t}$ value $\left.=2.062, p=.041, \eta^{2}=.339\right)$, problem integration $\left(\mathrm{t}\right.$-value $\left.=3.713, p<.001, \eta^{2}=.592\right)$, solution planning and monitoring $\left(\mathrm{t}\right.$-value $\left.=3.216, p=.002, \eta^{2}=.524\right)$, and solution execution $\left(\mathrm{t}\right.$-value $\left.=3.219, p=.002, \eta^{2}=.525\right)$ compared with the control group. On the other hand, there was a direct correlation between the students' pre-tests and posttests.

The statistical results mentioned above indicate that the scores of the post-test could have been influenced by the scores of the pre-test. To exclude the difference in initial ability to solve problems between the experimental group and the control group, pre-test scores were used and ANCOVA was adopted to treat these scores as a covariate.

Table 2. Discrepancy and correlation for problem-solving ability

\begin{tabular}{|c|c|c|c|c|}
\hline \multirow{2}{*}{ Test } & \multicolumn{2}{|c|}{ Experimental Group } & \multicolumn{2}{|c|}{ Control Group } \\
\hline & Pre (SD) & Post (SD) & Pre (SD) & Post (SD) \\
\hline \multirow{2}{*}{ Problem translation } & $84.16(13.48)$ & $93.23(8.87)$ & $79.21(15.66)$ & $83.60(15.92)$ \\
\hline & \multicolumn{2}{|c|}{ Correlation $=.506^{\star \star \star}$} & \multicolumn{2}{|c|}{ Correlation $=.565^{\star \star \star}$} \\
\hline \multirow{2}{*}{ Problem integration } & $86.11(13.20)$ & $90.17(10.35)$ & 76.46 (18.88) & $78.22(20.94)$ \\
\hline & \multicolumn{2}{|c|}{ Correlation $=.288^{\star \star \star}$} & \multicolumn{2}{|c|}{ Correlation $=.695^{* \star *}$} \\
\hline \multirow{2}{*}{$\begin{array}{l}\text { Solution planning and } \\
\text { monitoring }\end{array}$} & $72.87(19.88)$ & $84.14(16.23)$ & $62.39(20.10)$ & $65.84(21.24)$ \\
\hline & \multicolumn{2}{|c|}{ Correlation $=.588^{* * *}$} & \multicolumn{2}{|c|}{ Correlation $=.342^{* *}$} \\
\hline \multirow{2}{*}{ Solution execution } & $65.05(22.18)$ & $77.19(21.80)$ & $53.37(22.32)$ & $70.31(23.58)$ \\
\hline & \multicolumn{2}{|c|}{ Correlation $=.499^{* \star *}$} & \multicolumn{2}{|c|}{ Correlation $=.484^{* \star \star}$} \\
\hline
\end{tabular}




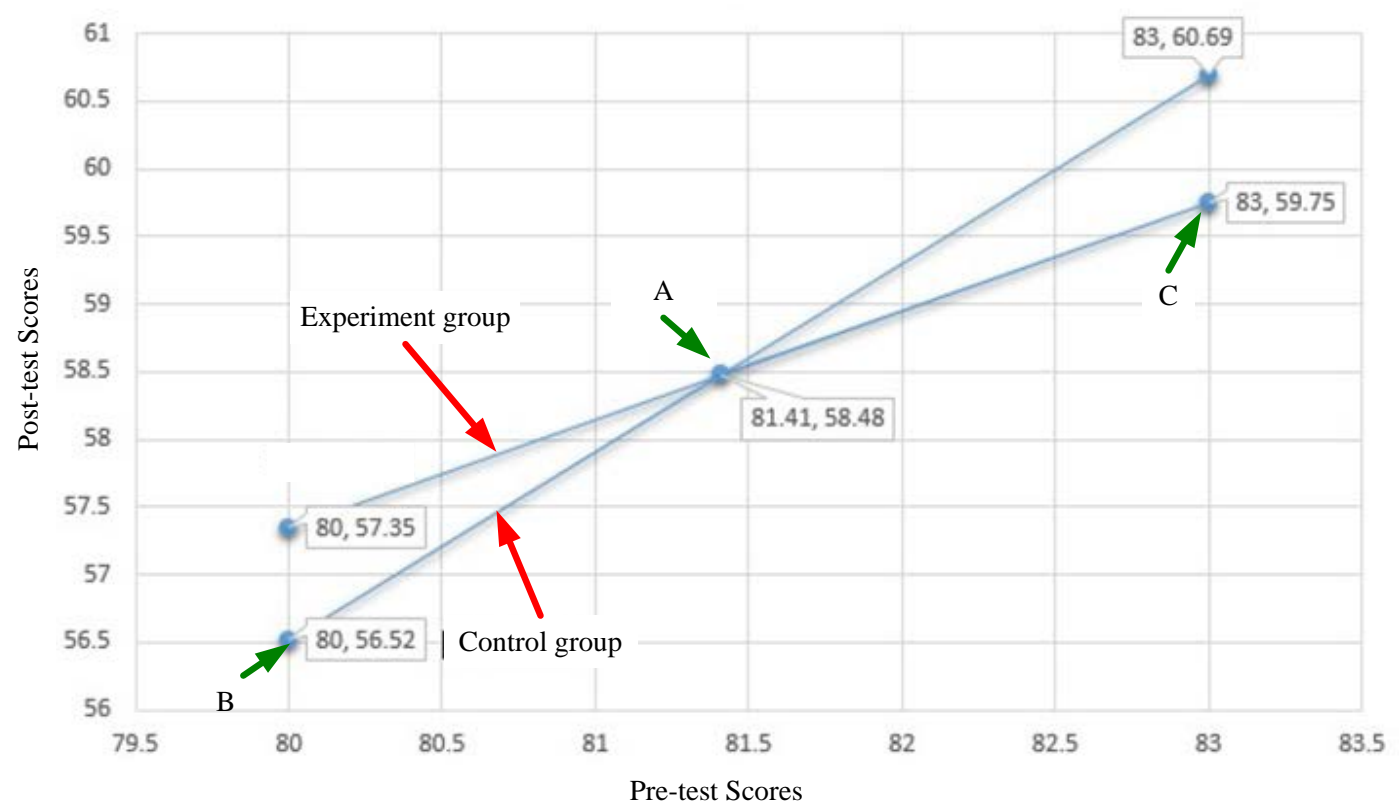

Figure 8. Cross point $(A)$ and significant difference points $(B$ and $C$ ) of the regression lines for the experimental group and the control group

In problem translation and problem integration, a test for homogeneity of variance was conducted, with the results revealing significant effects for problem translation $\left(\mathrm{F}_{1,149}=4.202, p=.042\right)$ and problem integration $\left(\mathrm{F}_{1,149}=\right.$ $17.316, p<.001$ ); that is, the two regression lines (the pre-test and the teaching strategies) did interact so the data did not meet the requirement for homogeneity of variance. The ANCOVA was replaced by the Johnson-Neyman method to find the cross point of the two regression lines and the locations of significant difference.

Figure 8 shows that the cross point (point A) was 81.41 and that of the two points of significant difference (points $\mathrm{B}$ and $\mathrm{C}$ ) was 80 and 83 , respectively, for the post-test scores for problem translation. This meant that traditional instruction was more helpful for students' problem translation ability when the pre-test scores of the students were below 80 . On the contrary, the PSADRI system was more helpful for students' problem translation ability when the pre-test scores of students were above 83 . Regarding the students whose pre-test scores on problem translation were between 80 and 83, no significant difference was observed in problem-solving ability between the experimental group and the control group. This statistical result supports Hypothesis 2a.

Figure 9 shows that the cross point (point A) for problem integration was 59.9 and that of the two points of significant difference (points B and C) was 58 and 61, respectively. This means that traditional instruction was more helpful for students' problem integration ability when their pre-test scores were below 58 . On the contrary, the PSADRI system was more helpful for students' problem integration ability when their pre-test scores were above 61. Regarding the students whose pre-test scores on problem integration were between 58 and 61, no significant difference in problem-solving ability was observed between the experimental group and the control group. This statistical result supports Hypothesis $2 b$.

ANCOVA results (see Table 3 ) indicated that when the effect of the covariant (pre-test of solution planning and monitoring) $\left(\mathrm{F}_{1,149}=.762, \mathrm{p}=.384\right)$ on the dependent variable (post-test of solution planning and monitoring) was deleted, there were significant main effects $\left(\mathrm{F}_{1,150}=24.541, p<.001\right.$, adj- $\left.\mathrm{R}^{2}=.256, \mathrm{\eta}^{2}=.141\right)$ on the pedagogical strategies between the two groups. After calculating the adjusted means of the experimental group $(M=26.43, S D$ $=.47$ ) and the control group $(\mathrm{M}=23.68, \mathrm{SD}=.47)$, it was found that the problem-solving ability of the experimental group was significantly better than that of the control group. This statistical result supports Hypothesis 2c.

Moreover, based on the premise that the pre-test was the covariate $\left(\mathrm{F}_{1,149}=.020, p=.888\right)$, the results showed an insignificant difference $\left(\mathrm{F}_{1,150}=.098, p=.754\right.$, adj- $\left.\mathrm{R}^{2}=.249, \mathrm{\eta}^{2}=.001\right)$ in the scores for solution planning and monitoring between the experimental group (adj- $\mathrm{M}=74.63$, adj-SD $=2.16$ ) and the control group (adj-M $=73.59$, adj-SD $=2.46$ ). This statistical result rejects Hypothesis $2 \mathrm{~d}$. 


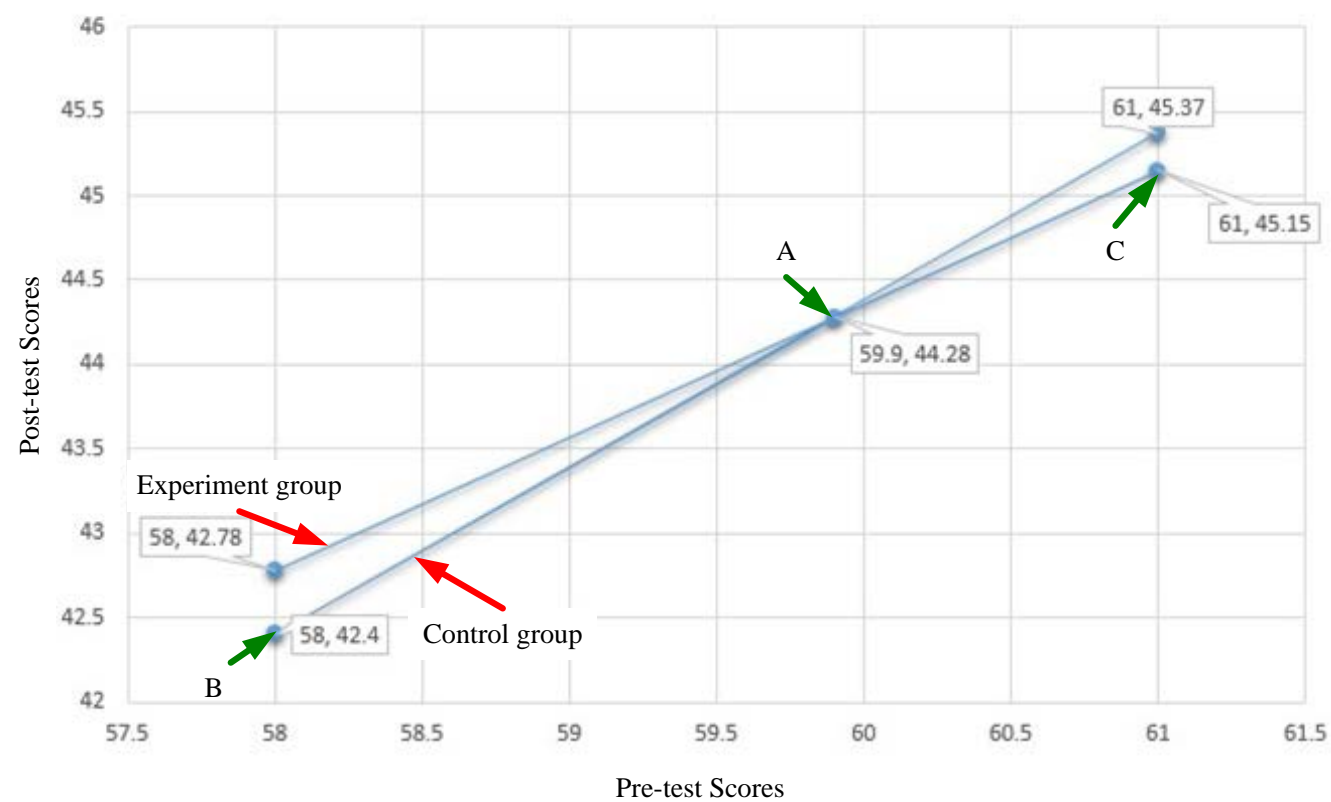

Figure 9. Cross point $(A)$ and significant difference points $(B$ and $C$ ) of the regression lines for the experimental group and the control group

Table 3. ANCOVA results of the assessment of the post-test scores

\begin{tabular}{lcccc}
\hline Tests & Homogeneity of Regression $(\boldsymbol{\rho})$ & $\boldsymbol{F}$-value $(\boldsymbol{\rho})$ of Pre-test & $\boldsymbol{F}$-value $(\boldsymbol{\rho})$ of Group $\mathbf{R}^{\mathbf{2}}$ (Adj $\left.\mathbf{R}^{2}\right)$ \\
\hline Problem translation & $4.202(.042)^{*}$ & - & - & - \\
\hline Problem integration & $17.316(<.001)^{* \star *}$ & - & - & - \\
\hline $\begin{array}{l}\text { Solution planning and } \\
\text { monitoring }\end{array}$ & $.762(.384)$ & $40.194(<.001)^{* * *}$ & $24.541(<.001)^{* * *}$ & $.365(.356)$ \\
\hline \begin{tabular}{l} 
Solution execution \\
\hline
\end{tabular} & $.020(.888)$ & $47.804(<.001)^{* \star *}$ & $.098(.754)$ & $.259(.249)$ \\
\hline
\end{tabular}

$\rho<0.05, "{ }^{* *} \rho<0.01,{ }^{* * *} \rho<0.001$

\section{Perceptions toward Mathematics Learning Using Different Pedagogical Strategies}

The paired-samples t-test was adopted to compare differences in students' perceptions toward mathematics based on the scores of the pre-tests and the post-tests taken by the two groups. Table 4 shows that there was an insignificant difference in attitude and interest $(\mathrm{t}$-value $=.585, p=.560)$, mathematical value ( $\mathrm{t}$-value $=.709, p=$ $.480)$, motivation, $(\mathrm{t}$-value $=.427, p=.671)$, and total scores $(\mathrm{t}$-value $=.653, p=.515)$ for the experimental group between the pre-test scores and the post-test scores. Likewise, the control group had no significant differences in attitude and interest $(\mathrm{t}$-value $=-1.635, p=.107)$, mathematical value ( $\mathrm{t}$-value $=-.995, p=.323)$, motivation, $(\mathrm{t}$-value $=-1.064, p=.291$ ), and total scores ( $\mathrm{t}$-value $=-1.337, p=.186$ ). The results revealed that there was positive improvement in students' perceptions toward mathematics learning when they used the PSADRI system, while the students who received the traditional instruction activity had negative perceptions toward mathematics learning. Moreover, the independent-sample t-test showed that the means of attitude and interest ( $\mathrm{t}$-value $=2.726, p=.007)$, mathematical value $(\mathrm{t}$-value $=3.007, p=.003)$, motivation, $(\mathrm{t}$-value $=3.766, p<.001)$, and total scores $(\mathrm{t}$-value $=$ $3.389, p=.001)$ in the experimental group were higher than in the control group in the post-test. The results revealed that the experimental group displayed a higher level of perceptions toward mathematics learning than the control group did. This statistical result supports Hypothesis 3. 
Table 4. Paired-samples t-test results of pre- and post-tests for students' perceptions toward mathematics learning

\begin{tabular}{lccccc}
\hline Factor & Group & Pre-test (SD) & Post-test (SD) & Difference & T-value \\
\hline Attitude and & Experimental & $33.92(9.51)$ & $34.35(9.31)$ & 0.43 & .585 \\
Interest & Control & $31.55(10.85)$ & $29.87(10.66)$ & -1.68 & -1.635 \\
\hline \multirow{2}{*}{$\begin{array}{l}\text { Mathematical } \\
\text { Value }\end{array}$} & Experimental & $38.48(8.18)$ & $39.14(8.63)$ & 0.66 & .709 \\
\hline \multirow{2}{*}{ Motivation } & Control & $35.51(9.12)$ & $34.46(10.61)$ & -1.05 & -.995 \\
\hline \multirow{2}{*}{ Total } & Experimental & $39.43(8.67)$ & $39.84(9.67)$ & 0.41 & .427 \\
\cline { 2 - 6 } & Control & $35.34(10.04)$ & $34.10(9.08)$ & -1.24 & -1.064 \\
\hline
\end{tabular}

$\rho<0.05,{ }^{* *} \rho<0.01,{ }^{* * *} \rho<0.001$

Table 5. Regression analyses of predictors of academic achievement using two pedagogical strategies

\begin{tabular}{|c|c|c|c|c|c|c|c|c|}
\hline \multirow{2}{*}{ Variables } & \multicolumn{4}{|c|}{ Experimental Group } & \multicolumn{4}{|c|}{ Control Group } \\
\hline & $\beta$ & $t$ & $\beta$ & $\mathbf{t}$ & $\beta$ & $\mathbf{t}$ & $\beta$ & $\mathbf{T}$ \\
\hline Pre-test & .631 & $3.332^{* *}$ & .497 & $4.098^{* * *}$ & .412 & $2.160^{*}$ & .088 & .611 \\
\hline \multicolumn{9}{|l|}{ Pre- } \\
\hline Problem translation & .022 & .200 & -.109 & -1.538 & .010 & .093 & -.043 & -.574 \\
\hline Problem integration & -.013 & -.128 & -.075 & -1.124 & .416 & $3.154^{\star *}$ & .200 & 1.992 \\
\hline $\begin{array}{l}\text { Solution planning and } \\
\text { monitoring }\end{array}$ & .067 & .586 & -.147 & -1.933 & .065 & .599 & .136 & 1.743 \\
\hline Solution execution & .063 & .491 & -.046 & -.570 & .020 & .193 & .015 & .208 \\
\hline \multicolumn{9}{|l|}{ Post- } \\
\hline Problem translation & & & .259 & $4.249^{* * *}$ & & & .289 & $3.667^{* *}$ \\
\hline Problem integration & & & .346 & $6.565^{* * *}$ & & & .063 & .812 \\
\hline $\begin{array}{l}\text { Solution planning and } \\
\text { monitoring }\end{array}$ & & & .090 & 1.261 & & & .213 & $2.937^{\star *}$ \\
\hline Solution execution & & & .383 & $5.907^{* * *}$ & & & .193 & $2.856^{* *}$ \\
\hline$R^{2}\left(\operatorname{Adj}-R^{2}\right)$ & \multicolumn{2}{|c|}{$.550(.522)$} & \multicolumn{2}{|c|}{$.835(.816)$} & \multicolumn{2}{|c|}{$.727(.704)$} & \multicolumn{2}{|c|}{$.875(.855)$} \\
\hline$\Delta \mathrm{R}^{2}$ & \multicolumn{4}{|c|}{$.285(.294)$} & & & \multicolumn{2}{|c|}{$.148(.151)$} \\
\hline $\mathrm{F}$ & \multicolumn{2}{|c|}{$19.557^{\star \star \star}$} & \multicolumn{2}{|c|}{$42.758^{\star \star *}$} & \multicolumn{2}{|c|}{$32.461^{\star \star \star}$} & \multicolumn{2}{|c|}{$44.397^{\star \star *}$} \\
\hline
\end{tabular}

\section{The Relationship between Pedagogical Strategies, Problem-solving Ability, and Academic Achievement}

To obtain a deeper understanding of the intricate relationship between pedagogical strategies, problem-solving ability, and academic achievement, two linear hierarchical regressions were performed on the data to measure the extent to which the pre-test achievement of problem solving ability (block 1 ) would positively predict the post-test achievement of problem solving ability (block 2) using the PSADRI system and traditional teaching approaches. The $\beta$ weights represented are illustrated in Table 5 .

The first hierarchical regression was executed to predict students' academic achievement in the experimental group (the PSADRI system). In block 1 , pre-test achievement $(\mathrm{t}=3.332, p=.001)$ strongly predicted post-test achievement $\left(\mathrm{F}_{5,80}=19.557, p<.001\right.$, adj- $\left.\mathrm{R}^{2}=.522\right)$, while the initial four problem-solving items were not found to be significant predictors of achievement. This statistical result supports Hypothesis $4 \mathrm{a}$.

In block 2 , these predictors strongly predicted post-test achievement $\left(\mathrm{F}_{9,76}=42.758, p<.001\right.$, adj- $\left.\mathrm{R}^{2}=.816\right)$. As shown in Table 5, the omnibus multivariate test indicated that three of the four problem-solving items (post-test) predicted post-test achievement. Problem translation $(t=4.249, p<.001)$, problem integration $(t=6.565, p<.001)$, and solution execution $(\mathrm{t}=5.907, p<.001)$ positively predicted post-test achievement; likewise, pre-test achievement $(\mathrm{t}=4.098, p<.001)$ strongly predicted post-test achievement. Solution planning and monitoring was not related to achievement. This statistical result supports Hypothesis $5 \mathrm{a}$.

Table 5 also shows the results of a hierarchical multivariate multiple regression analysis in which achievement was predicted by these predictors using the traditional teaching approach. In block 1 , initial academic achievement and pre-problem integration were significant predictors in the model $\left(\mathrm{F}_{5,61}=32.461, p<.001\right)$ and significantly accounted for $70.4 \%$ of the variance. This statistical result supports Hypothesis $4 \mathrm{~b}$.

In block 2, post-abilities to solve problems were entered as predictors $\left(\mathrm{F}_{9,57}=44.397, p<.001\right)$ and accounted for an additional $15.1 \%$ of the variance. Problem translation $(t=3.667, p=.001)$, solution planning and monitoring $(t=$ 
2.937, $p=.005)$, and solution execution ( $\mathrm{t}=2.856, p=.006)$, but not problem integration, were significant predictors in the model, while the pre-test was not a significant predictor. This statistical result supports Hypothesis $5 \mathrm{~b}$.

\section{DISCUSSION}

Much of the mathematics software available for learning mathematical concepts provides students with more opportunity for drill-and-practice strategies with tutorials and simulations (Pilli \& Aksu, 2013). Students can work on exercises in an interesting real-life-based context in the form of computer games or assessment through drilland-practice mathematics software (McCoy, 1996). The PSADRI system integrated drill-and-practice, assessment, and instruction software for mathematics education, as explained in the Methods section, and it was oriented around general problem-solving steps, interactive mathematical problem exercises, and solutions based on guided activities. The results of the students' assessments of problem-solving ability and academic achievement showed that both the experimental group and the control group increased their performance level when they worked on solving the problems and acquiring problem-solving skills. Many researchers (e.g., de-Marcos et al., 2016; Foster, Anthony, Clements, Sarama, \& Williams, 2016; Maier et al., 2016; Pilli \& Aksu, 2013; van der Kleij et al., 2012) believe that computer-based assessment and instruction is a powerful learning tool that affords many benefits to students, such as enhancing their learning performance, attracting their attention, and increasing their learning motivation.

The computer-assisted instruction software in many studies (e.g., Gunbas, 2015; Kanive, Nelson, Burns, \& Ysseldyke, 2014; McLaren, Adams, Mayer, \& Forlizzi, 2017) has been used in an experimental group but not in a control group. The results of the similar experimental design used in this study to compare the academic achievement of students revealed that there was a significant positive effect on the achievement of students' mathematics test scores in the experimental group. The annotation function and drawing board function in this study provided students with visual representations that facilitated their thinking about mathematical concepts, connecting the texts of the problems with illustrations. Chen, Wang, and Chen (2014) proved that the annotation function encouraged students to contribute high-quality annotations, which enhanced their reading comprehension ability. Moreover, Yung and Paas (2015) indicated that learning with visual representations resulted in higher learning performance and lower cognitive load than learning without visual representations. Zhang and Norman (1994) demonstrated that visual representations can relieve some of the limited working memory resources that are used to establish relationships between abstract mathematical concepts and their underlying functions; thus, students can acquire a deeper understanding and enhance their problem-solving ability.

Students could perform drill-and-practice step by step to achieve mastery in mathematics learning using the question-guided training function. Through diagnosis and analysis of the types of errors, student could obtain adequate remedial instruction to correct errors and improve their misunderstandings in the problem-solving process. Furthermore, the results in Table 3 revealed that students were learning how to master problem-solving skills, rather than learning by relying on the support tools. Adams et al. (2014) found that practice in identifying, explaining, and correcting errors may help students process decimal problems at a deeper level, and thereby help them overcome misconceptions and build a lasting understanding of decimals. Those results were consistent with the findings of other researchers (Maier et al., 2016; Sung et al., 2016; van der Kleij, Feskens, \& Eggen, 2015).

Based on the results in Table 4, no significant change in students' perceptions toward mathematics learning was found among the students in both groups. The change in perceptions toward mathematics learning was positive for the students in the experimental group, whereas the change in perceptions toward mathematics learning showed a small decrease in the control group. Previous experimental studies in the field have also argued that mathematics education integrated with computer-assisted technologies positively increased students' perceptions toward mathematics learning (Afari, Aldridge, Fraser, \& Khine, 2013; Birgin, Bozkurt, Gürel, \& Duru, 2015; McLaren et al., 2017; Pilli \& Aksu, 2013; Soliman \& Hilal, 2016). One reason to use computer-assisted software may be that it motivates students, as investing mental effort in instructional materials on a computer is seen as more "fun" than doing regular schoolwork (Kuiper \& de Pater-Sneep, 2014; Yung \& Paas, 2015).

According to the hierarchical regression results of the students' academic achievement in both groups, an interesting finding related to the use of the PSADRI system was found. Initial academic achievement (pre-test) was a stronger predictor of academic achievement in problem solving ability (post-test) in both groups. Pajares and Kranzler (1995) found that the initial level of mathematics had strong direct effects on performance. The result in Table 5 indicate that initial academic achievement was a stronger predictor in the experimental group than in the control group; meanwhile, the students' initial problem-solving ability scores were entered into block 1, and the four variables were insignificant predictors for both groups. Specifically, it is interesting that, when the post-test scores for problem-solving ability were entered into block 2, the variable of initial academic achievement was an insignificant predictor for both groups. For the experimental group, problem translation, problem integration, and solution execution were significant predictors of academic achievement (post-test); meanwhile, problem translation, solution planning and monitoring, and solution execution were significant predictors for the control 
group. These results indicate that guiding students to solve problems step by step can increase their deep processing of information. Educating students to engage in deep processing of information so that they can retain and then apply that information or skill to solve personal problems encountered in their daily or professional life is an important issue (León, Núñez, \& Liew, 2015). That is, the students' learning performance in both groups was enhanced when their ability to solve problems in four steps improved.

\section{CONCLUSION}

This study designed and developed a Problem-solving Assessment, Diagnosis, and Remedial Instruction (PSADRI) system. The PSADRI system is a learning-assisted tool that supports mathematics education to foster students' problem-solving ability. The main focus of this study was to examine the effects of different pedagogical strategies on first-year middle school students' problem-solving ability and academic achievement in mathematics.

\section{Contributions}

The major contributions of this study were middle school students' improved academic achievement in mathematics, problem-solving ability, and interest in learning mathematics via the PSADRI system, an individual teaching system. The PSADRI system supported mathematics education in a virtual environment to improve students' problem-solving ability. Moreover, the question-guided training function and instruction materials provided the students with more effective and convenient tools to practice mathematical word problems in accordance with their errors.

The 153 middle school students who participated in this experiment were divided into an experimental group (86 students who used the PSADRI system) and a control group (67 students who received traditional instruction). The results revealed that the PSADRI system provided students with a learning-assisted tool to achieve a greater learning performance in mathematics than the students who received traditional instruction, and the system also improved their problem-solving ability. The PSADRI system should be used in extracurricular activities generically so that students can develop a conceptual understanding of the process of problem-solving and can apply it effectively, efficiently, and flexibly across problem types.

\section{Research Limitations}

Two limitations of this study are important to note. First, Taiwan's parents believe that "to be a scholar is to be at the top of society; all occupations are at the base," which means that students rarely participate in extracurricular activities. Moreover, the right of a student to choose a course in middle school is limited in Taiwan's education system, and teachers can only lead students in participating in experimental activities in the class as a unit. Although 153 first-year middle school students were recruited, it was difficult to control for the students' desire to learn mathematics and their level of math ability. Second, the research duration was quite short (five weeks). A longitudinal design would be useful in assessing the cumulative effects of different pedagogical strategies on the changes in students' problem-solving ability over time.

\section{ACKNOWLEDGEMENTS}

This research is partially supported by the "Aim for the Top University Project" and "Center of Learning Technology for Chinese" of National Taiwan Normal University (NTNU), sponsored by the Ministry of Education, Taiwan, R.O.C. and the "International Research-Intensive Center of Excellence Program" of NTNU and Ministry of Science and Technology, Taiwan, R.O.C. under Grant no. MOST 103-2511-S-003-051-MY3, 103-2511-S-003-064MY3, 104-2511-S-003-041-MY3, 105-2511-S-003-049-MY3, 106-2511-S-003-019-MY3, 106-2622-S-003-002-CC2.

\section{REFERENCES}

Adams, D. M., McLaren, B. M., Durkin, K., Mayer, R. E., Rittle-Johnson, B., Isotani, S., \& Van Velsen, M. (2014). Using erroneous examples to improve mathematics learning with a web-based tutoring system. Computers in Human Behavior, 36, 401-411.

Afari, E., Aldridge, J. M., Fraser, B. J., \& Khine, M. S. (2013). Students' perceptions of the learning environment and attitudes in game-based mathematics classrooms. Learning Environments Research, 16(1), 131-150.

Baltacı, S., Yıldız, A., \& Güven, B. (2014). Knowledge types used by eighth grade gifted students while solving problems. Bolema: Boletim de Educação Matemática, 28(50), 1032-1055. 
Birgin, O., Bozkurt, E., Gürel, R., \& Duru, A. (2015). The effect of computer-assisted instruction on 7th grade students' achievement and attitudes toward mathematics: The case of the topic "Vertical Circular Cylinder". Hrvatski časopis za odgoj i obrazovanje, 17(3), 783-813.

Bjork, I. M., \& Bowyer-Crane, C. (2013). Cognitive skills used to solve mathematical word problems and numerical operations: A study of 6-to 7-year-old children. European Journal of Psychology of Education, 28(4), 1345-1360.

Boonen, A. J., van Wesel, F., Jolles, J., \& van der Schoot, M. (2014). The role of visual representation type, spatial ability, and reading comprehension in word problem solving: An item-level analysis in elementary school children. International Journal of Educational Research, 68, 15-26.

Brown, N., Fluck, A., Wilson, K., \& Fitzallen, N. (2008). Meeting the challenge: Professional learning for integrating ICT into science and mathematics classes. Paper presented at the AARE.

Burguillo, J. C. (2010). Using game theory and competition-based learning to stimulate student motivation and performance. Computers $\mathcal{E}$ Education, 55(2), 566-575.

Chen, C. M., Wang, J. Y., \& Chen, Y. C. (2014). Facilitating English-language reading performance by a digital reading annotation system with self-regulated learning mechanisms. Journal of Educational Technology $\mathcal{E}$ Society, 17(1).

Chen, M. Y., \& Yu, C. Y. (2013). Using trends in mathematics and science study to investigate the effects of ability beliefs and task values on eighth-grader mathematics achievements in Taiwan. Journal of Research in Education Sciences, 58(3), 153-186.

Chin, E. T., Lin, Y. C., Lin, C. P., \& Tuan, H. L. (2009). The influence of mathematics inquiry teaching on mathematical problem solving abilities: Four 7th grade students case study. Research and Development in Science Education Quarterly, 55, 83-116.

Croft, A. C., Danson, M., Dawson, B. R., \& Ward, J. P. (2001). Experiences of using computer assisted assessment in engineering mathematics. Computers $\mathcal{E}$ Education, 37(1), 53-66.

de-Marcos, L., Garcia-Lopez, E., \& Garcia-Cabot, A. (2016). On the effectiveness of game-like and social approaches in learning: Comparing educational gaming, gamification \& social networking. Computers $\mathcal{E}$ Education, 95, 99-113.

Elia, I., van den Heuvel-Panhuizen, M., \& Kolovou, A. (2009). Exploring strategy use and strategy flexibility in nonroutine problem solving by primary school high achievers in mathematics. ZDM, 41(5), 605.

Erbas, A. K., \& Okur, S. (2012). Researching students' strategies, episodes, and metacognitions in mathematical problem solving. Quality \& Quantity, 46(1), 89-102.

Figueira-Sampaio, A. d. S., dos Santos, E. E. F., \& Carrijo, G. A. (2009). A constructivist computational tool to assist in learning primary school mathematical equations. Computers E Education, 53(2), 484-492.

Foster, M. E., Anthony, J. L., Clements, D. H., Sarama, J., \& Williams, J. M. (2016). Improving mathematics learning of kindergarten students through computer-assisted instruction. Journal for Research in Mathematics Education, 47(3), 206-232.

Ge, X., \& Land, S. M. (2003). Scaffolding students' problem-solving processes in an ill-structured task using question prompts and peer interactions. Educational Technology Research and Development, 51(1), 21-38.

Gunbas, N. (2015). Students' mathematics word problem-solving achievement in a computer-based story. Journal of Computer Assisted Learning, 31(1), 78-95.

Hsiao, H. S., Chang, C. S., Chen, C. J., Wu, C. H., \& Lin, C. Y. (2015). The influence of Chinese character handwriting diagnosis and remedial instruction system on learners of Chinese as a foreign language. Computer Assisted Language Learning, 28(4), 306-324.

Hsiao, H. S., Chang, C. S., Lin, C. Y., \& Wang, Y. Z. (2016). Weather observers: A manipulative augmented reality system for weather simulations at home, in the classroom, and at a museum. Interactive Learning Environments, 24(1), 205-223.

Hsiao, H. S., Chang, C. S., Lin, C. Y., Chang, C. C., \& Chen, J. C. (2014). The influence of collaborative learning games within different devices on student's learning performance and behaviours. Australasian Journal of Educational Technology, 30(6).

Hsiao, H. S., Chang, C. S., Lin, C. Y., Chen, B., Wu, C. H., \& Lin, C. Y. (2016). The development and evaluation of listening and speaking diagnosis and remedial teaching system. British Journal of Educational Technology, 47(2), 372-389.

Kanive, R., Nelson, P. M., Burns, M. K., \& Ysseldyke, J. (2014). Comparison of the effects of computer-based practice and conceptual understanding interventions on mathematics fact retention and generalization. The Journal of Educational Research, 107(2), 83-89. 
Kim, M. C., \& Hannafin, M. J. (2011). Scaffolding problem solving in technology-enhanced learning environments (TELEs): Bridging research and theory with practice. Computers $\mathcal{E}$ Education, 56(2), 403-417.

Kloosterman, P., \& Stage, F. K. (1992). Measuring beliefs about mathematical problem solving. School Science and Mathematics, 92(3), 109.

Kuiper, E., \& de Pater-Sneep, M. (2014). Student perceptions of drill-and-practice mathematics software in primary education. Mathematics Education Research Journal, 26(2), 215-236.

Lee, C. Y., \& Chen, M. P. (2009). A computer game as a context for non-routine mathematical problem solving: The effects of type of question prompt and level of prior knowledge. Computers E Education, 52(3), 530-542.

León, J., Núñez, J. L., \& Liew, J. (2015). Self-determination and STEM education: Effects of autonomy, motivation, and self-regulated learning on high school math achievement. Learning and Individual Differences, 43, 156163.

Lester, F. K. (1994). Musings about mathematical problem-solving research: 1970-1994. Journal for Research in Mathematics Education, 25(6), 660-675.

Lin, C. C. (2007). The verification of relationship among expectancy, value, and mathematic achievement by structural equation modeling. Educational Review, 29, 103-127.

Maier, U., Wolf, N., \& Randler, C. (2016). Effects of a computer-assisted formative assessment intervention based on multiple-tier diagnostic items and different feedback types. Computers $\mathcal{E}$ Education, 95, 85-98.

Martín, S., \& Rubio, R. (2009). Parallax cues in the design of graphics used in technical education to illustrate complex spatial problems. Computers E Education, 53(2), 493-503.

Mayer, R. E. (1992). Thinking, problem solving, cognition: WH Freeman/Times Books/Henry Holt \& Co.

McCoy, L. P. (1996). Computer-based mathematics learning. Journal of Research on Computing in Education, 28(4), 438-460.

McLaren, B. M., Adams, D. M., Mayer, R. E., \& Forlizzi, J. (2017). A computer-based game that promotes mathematics learning more than a conventional approach. International Journal of Game-Based Learning (IJGBL), 7(1), 36-56.

Pajares, F., \& Kranzler, J. (1995). Self-efficacy beliefs and general mental ability in mathematical problem-solving. Contemporary Educational Psychology, 20(4), 426-443.

Pape, S. J., \& Wang, C. (2003). Middle school children's strategic behavior: Classification and relation to academic achievement and mathematical problem solving. Instructional Science, 31(6), 419-449.

Pilli, O., \& Aksu, M. (2013). The effects of computer-assisted instruction on the achievement, attitudes and retention of fourth grade mathematics students in North Cyprus. Computers \& Education, 62, 62-71.

Pintrich, P. R., \& De Groot, E. V. (1990). Motivational and self-regulated learning components of classroom academic performance. Journal of Educational Psychology, 82(1), 33.

Rau, P. L. P., Gao, Q., \& Wu, L.-M. (2008). Using mobile communication technology in high school education: Motivation, pressure, and learning performance. Computers $\mathcal{E}$ Education, 50(1), 1-22.

Schoenfeld, A. (2009). Learning to think mathematically: Problem solving, metacognition, and sense-making in mathematics. Coleccio $\square$ n Digital Eudoxus, (7).

Schoenfeld, A. H. (2014). Mathematical problem solving. Elsevier.

Schoppek, W., \& Tulis, M. (2010). Enhancing arithmetic and word-problem solving skills efficiently by individualized computer-assisted practice. The Journal of Educational Research, 103(4), 239-252.

Sim, G., Holifield, P., \& Brown, M. (2004). Implementation of computer assisted assessment: Lessons from the literature. ALT-J, 12(3), 215-229.

Snow, R. E., Corno, L., \& Jackson III, D. (1996). Individual differences in affective and conative functions. In D. C. Berliner \& R. C. Calfee (Eds.), Handbook of educational psychology (pp. 243-310). London, UK: Prentice Hall International.

Soliman, M. M., \& Hilal, A. J. (2016). Investigating the effects of computer-assisted instruction on achievement and attitudes towards mathematics among seventh-grade students in Kuwait. International Journal for Technology in Mathematics Education, 23(4).

Sung, Y. T., Liao, C. N., Chang, T. H., Chen, C. L., \& Chang, K. E. (2016). The effect of online summary assessment and feedback system on the summary writing on 6th graders: The LSA-based technique. Computers $\mathcal{E}$ Education, 95, 1-18.

Szetela, W., \& Nicol, C. (1992). Evaluating problem solving in mathematics. Educational Leadership, 49(8), 42-45. 
van der Kleij, F. M., Eggen, T. J. H. M., Timmers, C. F., \& Veldkamp, B. P. (2012). Effects of feedback in a computerbased assessment for learning. Computers \& Education, 58(1), 263-272.

van der Kleij, F. M., Feskens, R. C., \& Eggen, T. J. (2015). Effects of feedback in a computer-based learning environment on students' learning outcomes: A meta-analysis. Review of Educational Research, 85(4), 475-511.

Verschaffel, L., De Corte, E., Lasure, S., Van Vaerenbergh, G., Bogaerts, H., \& Ratinckx, E. (1999). Learning to solve mathematical application problems: A design experiment with fifth graders. Mathematical Thinking and Learning, 1(3), 195-229.

Walkington, C., Clinton, V., Ritter, S. N., \& Nathan, M. J. (2015). How readability and topic incidence relate to performance on mathematics story problems in computer-based curricula. Journal of Educational Psychology, 107(4), 1051.

Whitby, P. J. S. (2013). The effects of Solve It! on the mathematical word problem solving ability of adolescents with autism spectrum disorders. Focus on Autism and Other Developmental Disabilities, 28(2), 78-88.

Wilson, J. W., Fernandez, M. L., \& Hadaway, N. (1993). Mathematical problem solving. Research Ideas for the Classroom: High School Mathematics, 57-78.

Yung, H. I., \& Paas, F. (2015). Effects of computer-based visual representation on mathematics learning and cognitive load. Journal of Educational Technology \& Society, 18(4), 70.

Zhang, J., \& Norman, D. A. (1994). Representations in distributed cognitive tasks. Cognitive Science, 18(1), 87-122.

\section{http://www.ejmste.com}

